a condition of affairs as here described." This inference is entirely unwarranted by facts as they existed during and after the battle of Santiago.

The correspondent and editorial do not even mention the steamer Olivette we found July 7 anchored close to the shore before Siboney. This steamer, in command of Major Appel, U. S. A., was used as a hospital ship. This ship was in place and ready to receive the wounded during the battle. The steamer, at the time mentioned, had on board 300 wounded, who received the best surgical attention and nursing. The next day the steamer left for the United States, the medical staff being reinforced by the addition of Acting AssistantSurgeon Brown of Chicago from the Relief. General Stern. berg at an early date recognized the importance of hospital ships during this war. The Olivette was chartered for this special purpose, was well equipped and reached the seat of war in time. The hospital ship Relief, formerly the John Englis, under the supervision of its commander, Major Torrey, was transformed into an ideal floating hospital in less than six weeks and reached Siboney July 7 , a day before the Olivette left for its home port. Do these things show either negligence or ignorance? Do they not rather demonstrate foresight and an earnest endeavor to better care for the sick and wounded in a way creditable to our country and the chief of the Medical Department? This question can safely be left for the wounded to answer. The Surgeon-General accepted the legitimate services of the Red Cross Association and had reason to expect aid from this source, should pressing emergencies present themselves. The medical officers, the wounded and the sick have every reason to be grateful to Miss Clara Barton, for what she did in furnishing ice, delicacies and medical supplies. The State of Texas did excellent work in aiding the Medical Department, but that is no reason why those connected with the Red Cross Association should claim all the credit and undertake to criticise a department of the government which has done all it possibly could in anticipating the requirements of a sudden emergency. It is a source of great regret that there should be any friction whatever between the Medical Department and the friends and sup. porters of the Red Cross Association. It must be clear to every unprejudiced mind that the treatment of the sick and wounded must remain under the direct care, control and man. agement of the Medical Department, and that the function of Red Cross is rather auxiliary to it than as an independent organization if the greatest amount of good is to be realized from it. The hospital ship Relief brought an immense amount of medical supplies, delicacies, cots, pillows and biankete. When we arrived at Siboney we knew our presence was much reeded, and looked in vain for some one to inform us where and how to land. The precipitous and rocky nature of the shore and the great depth of the ocean made it unfavorable to secure anchorage for several days. A single lighter attended to the demands of numerous transport ships. I am sure no one could blame the Medical Department for the unavoidable delay in unloading the supplies. The little steam launches did what could be done in bringing to the shore what was most needed. Major Torrey worked night and day in supplying the requisitions made by the surgeons in the field and hospitals. There was no red tape here, all they had to do was to inform him what was wanted and it was delivered as soon as it could be brought to the shore. The lack of proper transportation facilities from the landing to the front can not be charged to the Medical Department. It took more than a week of the hardest kind of work to land all of the supplies, and, considering the limited facilities available, it is and always must $b e$ regarded as a source of satisfaction that it was made possible at all. The Relief brought 1000 cots and an ample supply of bankets, which reached the hospitals with as little delay as possible.
Ijieut. Crabbs of the 8th Cavalry, showed a creditable degree of ingenuity, energy and often of courage in landing the sup. plies. The complaint that the sick and wounded lacked medicines and dressing materials is true only to a certain extent. Some of the medicines were exhausted, owing to the unexpected enormous demand, but they were supplied as quickly as could be done under the existing circumstances. The writer had the privilege to operate in all of the hospitals and was always able to find the essential antiseptics and dressing materials required in military practice, and this was at a time when the supplies were at the lowest. There was no lack at any time of stimulants and anesthetics. There is no use in denying the fact that immediately after the battle the tentage and blanket supply were inadequate, but these defects were corrected promptly. War always has had its hardships and discomforts; it can not be prosecuted in parlor cars and clubhouses. Or soldiers expected deprivations and unavoidable discomforts, but on the whole they were subjected to less actual suffering than they had reason to look for. To the credit of the medical officers it must be said they shared the inevitable hardships with the soldiers. They lived on the same food, drank the same water and made the moist ground their beds. The writer will always cherish the memory of the hardships incident to a campaign in a foreign country, a tropical climate and among a strange people. The Cuban campaign was planned and executed so quickly that some omissions and defects had to be expected. It is a source of gratification to know that the complaints made against the medical department have come from newspaper correepondents and camp followers more than from the soldiers themselves. Among the thousands of sick and wounded with whom I have been brought in contact during the Cuban campaign I have seldom heard a complaint; on the contrary, I have heard nothing but words of praise for the hard-working, self-sacrificing medical officers and the department they represent in the field.

\section{Ice-Water Enteroclysis in Typhoid Fever.}

\section{Toledo, OHio, A ug. 1, 1998.}

To the Editor:-After having had favorable results with ice. water flushings of the bowels in the lowering of high temperatures in typhoid fever, I have wondered that greater stress is not laid upon the use of the measure by those who write upon the treatment of that disease.

The cases are few in number in which I have had the opportunity to test the practice, and it may be that these few cases were such as would have done well under the Brand method, the wet pack, or any other plan of refrigeration; indeed, such is doubtless true.

For several reasons though, my practice, limited as it is, leads me to look upon ice-water enteroclysis as superior to any other method of lowering the temperature which I have seen used.

In the first place, fever patients need much more water than they in their semicongcious condition are likely to ask for, or than they will drink when it is offered them, and it is always the fact that there is less water passed in to the bedpan than was forced in to the bowel.

I place this reason first because I believe it is important that these patients take into the system more water than they are accustomed to drink even in health, and sterilized water to which has been added common salt, thrown in to the bowels, is a rational way of meeting a vital requirement.

I do not know how high the water ascends in the bowels, but that it does hasten the removal of poisonous material from the bowels there can be no doubt. I believe, too, that subsequent injections ascend higher than the first ones did, the bowels becoming more accustomed to the water. The formation of intestinal gases is diminished by the cleansing of the bowel, and the soft rubber rectal tube frequently reaches an 
accumulation of gas, thereby relieving a troublesome tympanitis as weil.

Patients are not frightened or fatigued by the operation, but, on the contrary, so far as can be told by the expression of countenance, and by their general condition, are made more comfortable by it.

When the temperature is low, nervous manifestations are usually quiet, but whether this quiet is caused by a direct influence upon the nervous system or whether the nervousness is secondary to high temperature is a matter for individual speculation, but $I$ believe that the heat centers are quite as apt to be influenced for good by the abstraction of heat from the interior of the abdominal cavity as they are by radiation from the surface of the body.

Enteroctysis is much easier to administer than is any kind of bath, and hence is much surer of being properly attended to. The technic is simple.

A long, soft, rubber catheter is slipped upon the ordinary hard tip, a napkin is tightly wound around the tip until a hard ball is formed which is to be pressed against the anus to prevent the ejection of the enema. The catheter is oiled with petrolatum and as soon as the tip has entered the anus the water is permitted to flow and, by rotating the catheter to and fro with the fingers, it floats upward as the water expands the intestine, and used in this way it does not double upon itself, or cause rectal irritation. The instrument is retained in the bowel for twenty minutes, the nurse maintaining pressure upon the anus during the time, and when the water is allowed to come away it is found to have the temperature of the bowel. The fountain should not be higher than a foot above the patient's body.

The patient weighs 150 pounds and his temperature is 105 degrees, $150 \times 105=15,750$. Water, four pounds, at 32 degrees, is introduced. The heat which this abstracts from the body is the difference between 32 degrees and 105 degrees $\times 4=292$. The original heat units, $15,750-292=15,458 ; 15,458 \div 150=103$; and it has been my experience that the axillary temperature a half hour after the enema could be predicted with almost the above mathematic exactness.

J. S. Tracy, M. D.

$306 \mathrm{~W}$. Woodruff Ave.

\section{Flannel Underclothing for Soldiexs.}

Clinton, Ill., Aug. 6, 1898.

To the Editor:-There has been a good deal said of late about our soldiers in Cuba wearing abdominal bandages, "cholera pads" to protect them from dieeases of hot climates. I do not think much of the pad. I think it would be better protection and more sensible to furnish each man with two paire of flannel drawers, which would protect the soldier's legs as well as his abdomen. The extra pair could be kept dry and clean ready for a change and would make but little additional weight or bulk to carry.

I agree with Surgeon-General Sternberg that the field is no place for female nurses. They are all right in the local hospitale, but the battle-field and on the march is not their place. It was so during the Civil War and it can not be otherwise in the war with Spain.

JoHN WRIGHT, M.D.

\section{Proposed New Designation.}

San Diego, Cal., Aug. 3, 1898.

To the Editor:-With the advent of a new century the time is propitious for dropping such meaningless appellations as "Old School," "Regular," "Allopath," etc. Why not, henceforth adopt the eminently distinctive and appropriate title, "New School of Scientific Medicine," suggested by SurgeonGeneral Sternberg in his recent address at Denver?

Faithfully yours,

C. M. FENN, M.D.

\section{ASSOCIATION NEWS.}

Comment on Association Proceedings. - In connection with the proceedings of the Association of American Medical Colleges. published in this number, it is well to note a resolution adopted by the American Medical Association, which is farreaching in its effects. The resolution was introduced by Dr. Dudley S. Reynolds of Louisville, the president of the Judicial Council of the College Association; it was referred to the business committee, approved by it, and adopted with no opposition. (For resolution vide Journal, July 9, p. 83.) This resolution practically makes a new qualification for membership for every County society in affiliation with the AMERICAN Medical Association, since one cannot enjoy the full privileges of membership unless he is eligible to serving his society as a delegate to the American Medical Association, and it is a question whether the Association was competent to adopt it in this form, for it is, in effect, an amendment to the constitution. It is not to call attention to this structural weakness but rather to its dynamics. That a resolution of this character could be presented to two successive general sessions of the American Medical Association and not be adversely discussed, even by the benevolent advocate of the poor young man who must struggle to enter the profession at all, and therefore should receive a training making many of his class monuments of ignorance and incompetency, seems almost too wonderful to be true. Whatever may have been the private opinion of many who kept silent, public sentiment is in favor of a fitting educational period for the intending physician. We congratulate the College Association on their having the stamp of approval set upon their own standard, and, which is a source of greater gratulation, the decision of condemnation upon any course less thorough than their own,-Bulletin Am. Acad. Med., August, 1898.

Politics in the American Medical Association.-If one may judge by the tone of a recent editorial in the Ohio Medical Journal, in spite of the fact that Columbus is the meeting-place of the American Medical Association for next year, there is not an abiding peace in the minds of the profession of that State. There is a good deal of truth in the statement of the Ohio Medical Journal that "the political part of the convention continues to be managed by medical politicians; these gentlemen constitute a sect apart, come chiefly from St. Louis and Louisville, and come with everything cut and dried,' but granting it, there are many who will not give the matter the prominence which it evidently receives at the hande of our contemporary. Most of the members attend the sessions of the AmErican Medical Association for other reasons and with other purposes than to engage in political bickerings, and are only too glad that there are some who are willing to do this work for them. If they think they are running the show, let them think so as long as the performance continues; they get but an empty honor, forgotten before the next session, and have a great deal of labor for their pains. While they are doing this work the rest of us can meet and chat with friends, attend Sections, visit places of interest and enjoy ourselves. The men who are so unfortunate as to be elected to office will earn all they get from the honor, scores of times over, before next June.-Atlantic Med. Weekly, August 6.

Resolutions Submitted to the American Medical Association at the Denver Meeting, June 8, 1898, by W. H. Sandere, M.D., Health Officer of Alabama. (Vide Jourval, No. 2, Vol, xxxi, pp. 85 and 95 , July 19, 1898). Finally referred to the Business Committeo :

WHEREAs, The protection of the public health is one of the duties and functions of all well-organized and progressive governments ; therefore, be it

Resolved, 1 . That it is the sense of this body that a public health system correct in principle, complete in detail and appli- 